\title{
Principles for the wise use of computers by children
}

\author{
L. Straker ${ }^{\mathrm{a} *}$, C. Pollock ${ }^{\mathrm{b}}$ and B. Maslen ${ }^{\mathrm{a}}$ \\ ${ }^{a}$ School of Physiotherapy, Curtin University of Technology, GPO Box U1987, Perth, WA 6845, Australia; ${ }^{b}$ School of Psychology, \\ Curtin University of Technology, GPO Box U1987, Perth, WA 6845, Australia
}

\begin{abstract}
Computer use by children at home and school is now common in many countries. Child computer exposure varies with the type of computer technology available and the child's age, gender and social group. This paper reviews the current exposure data and the evidence for positive and negative effects of computer use by children. Potential positive effects of computer use by children include enhanced cognitive development and school achievement, reduced barriers to social interaction, enhanced fine motor skills and visual processing and effective rehabilitation. Potential negative effects include threats to child safety, inappropriate content, exposure to violence, bullying, Internet 'addiction', displacement of moderate/vigorous physical activity, exposure to junk food advertising, sleep displacement, vision problems and musculoskeletal problems. The case for child specific evidence-based guidelines for wise use of computers is presented based on children using computers differently to adults, being physically, cognitively and socially different to adults, being in a state of change and development and the potential to impact on later adult risk. Progress towards child-specific guidelines is reported. Finally, a set of guideline principles is presented as the basis for more detailed guidelines on the physical, cognitive and social impact of computer use by children. The principles cover computer literacy, technology safety, child safety and privacy and appropriate social, cognitive and physical development. The majority of children in affluent communities now have substantial exposure to computers. This is likely to have significant effects on child physical, cognitive and social development. Ergonomics can provide and promote guidelines for wise use of computers by children and by doing so promote the positive effects and reduce the negative effects of computer-child, and subsequent computer-adult, interaction.
\end{abstract}

Keywords: children; computers; guidelines

\section{Introduction}

Ergonomics aims to optimise the interaction between people and technology. The development of personal computers in the late twentieth century led to a major change in the technology many people interacted with. Considerable ergonomics research has focused on the physical and cognitive impact of computer use in adults, with the subsequent development of guidelines in an attempt to optimise the interaction. However, limited ergonomics research has focused on the interaction between children and computers. This is despite a higher proportion of children using computers than adults and a concern that habits developed during childhood may track into adulthood.

This paper aims to: 1) highlight the substantial exposure that children have to computers; 2) review the evidence for positive and negative impacts of computer use in children; 3) argue the need for child-specific evidence-based guidelines for wise computer use; 4) present a set of guideline principles as the basis for subsequent detailed guidelines.

\section{Children have substantial and varied exposure to computers}

\subsection{Computer use by children is internationally common, frequent and for substantial durations}

Many children in the current generation have never experienced a world without computers. An Australian 10 -year-old child was born at a time when $42 \%$ of Australian households already had a home computer (Australian Bureau of Statistics 1998). A 2-year-old Indian child was born into a country that had more than 50 million Internet users (Computer Industry Almanac 2006). It is therefore unsurprising that children themselves are using computers for substantial durations, frequently and from a young age. Figure 1 shows the percentage of Australian children using computers and the Internet in 2006 (Australian Bureau of Statistics 2006).

Children in Hong Kong aged from 12-16 years reportedly average $2.5 \mathrm{~h}$ per day using a computer for homework, surfing the Internet, communicating with others and playing games (Ho and Lee 2001). USA children of a similar age (11-14 years) average just over

*Corresponding author. Email: L.Straker@curtin.edu.au

ISSN 0014-0139 print/ISSN 1366-5847 online

(C) 2009 Taylor \& Francis

DOI: $10.1080 / 00140130903067789$

http://www.informaworld.com 
$1 \mathrm{~h}$ per day outside school (Roberts et al. 2005). Children use computers frequently. Recent Australian statistics showed that $45 \%$ of $12-14$ year old Australian children used a computer every day, with a further $46 \%$ using a computer between 2 and $6 \mathrm{~d}$ per week (Australian Bureau of Statistics 2006). Even very young children have been shown to be using computers. In the USA, $27 \%$ of 5-6 year olds used a computer for an average of $64 \mathrm{~min}$ on a typical day (Rideout et al. 2003) and more than half of 5-year-old Australian children use a computer each week (Straker et al. 2006c).

\subsection{School computer use}

School computer access is a priority in many countries, with governments as far afield as Macedonia and Australia currently aiming to provide one computer for each child at school (see Figure 2). Common computer tasks performed at school include word processing, searching for information on the web, using charts, graphs and educational software (Kent and Facer 2004).

Children's exposure to computer use at school varies widely. Many schools have only one or two short lessons per week, while other schools have fully embraced the new information technology and have implemented portable computer policies. At the latter schools students have their own portable PC, such as a tablet or laptop computer, which is transported to and from school each day. This can result in very high usage: two-thirds of students in such a school reported using their tablet computer for more than $4 \mathrm{~h}$ per day in a study of US children aged 16-18 years (Sommerich et al. 2007). More than 3 h daily use was reported for 10-17 year old Australian children in schools with mandatory laptop programmes (Harris and Straker 2000).

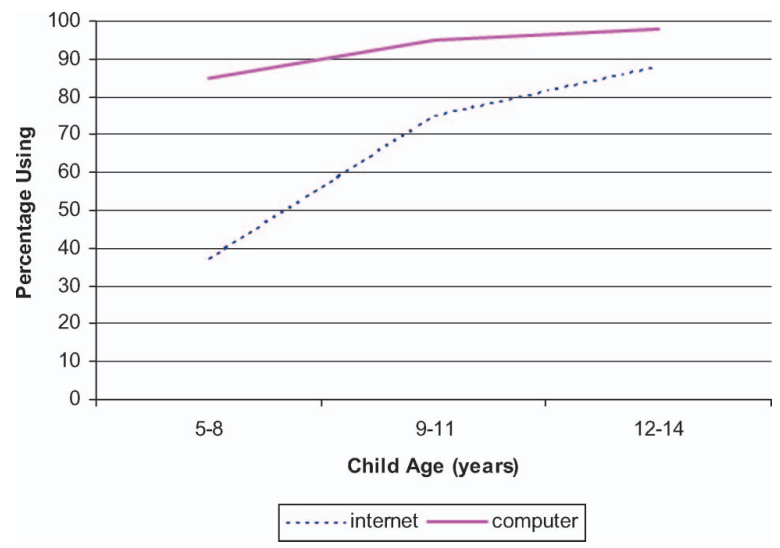

Figure 1. Percentage of children using computer and Internet by age group.
School computers may be shared by two or more children, particularly in the younger age groups (Sotoyama et al. 2002, Breen et al. 2007). This implies that the screen may be angled to one or both viewers, which has been shown to affect muscle activity and be related to greater musculoskeletal discomfort in university students (Szeto and Sham 2008).

\subsection{Home computer use}

Home computer access is also commonplace in many countries, with substantial research relating to the 'digital divide' between those who have and do not have access to computers (e.g. Kent and Facer $2004-$ UK, Roberts et al. 2005 - USA, Koivusilta et al. 2007 - Finland). Children without home access are less likely to use a computer on a given day, in spite of access often being available at local schools and libraries (Roberts et al. 2005). Children regularly use home computers for playing games, communication (email, messaging and online chat), word-processing and data entry, web surfing, downloading music (including peer-to-peer file sharing) and commercial purposes (see Figure 3).

According to Kent and Facer (2004), children view computers as being inherently connected, with many children believing that they would be unlikely to use their home computer if it was not connected to the Internet. This connectivity is further highlighted by the use of instant messaging, which is an ongoing activity concurrent with all other home computer use for many children.

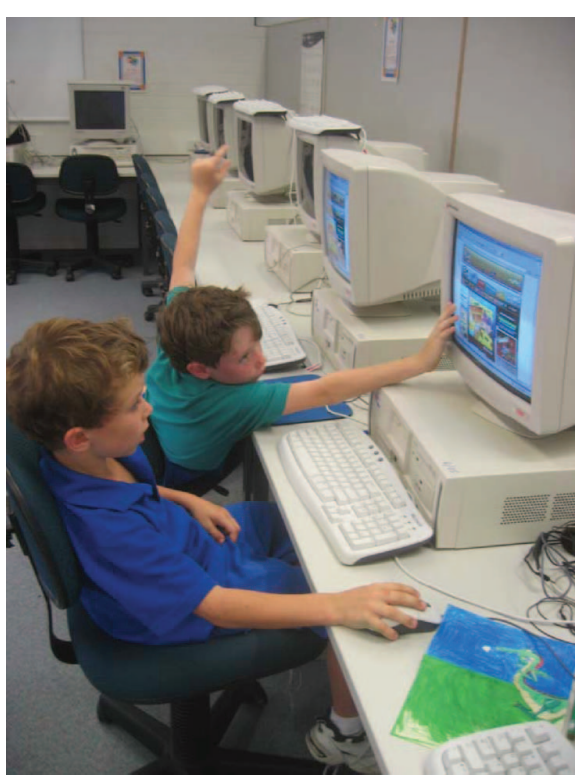

Figure 2. Use of computers at school. 


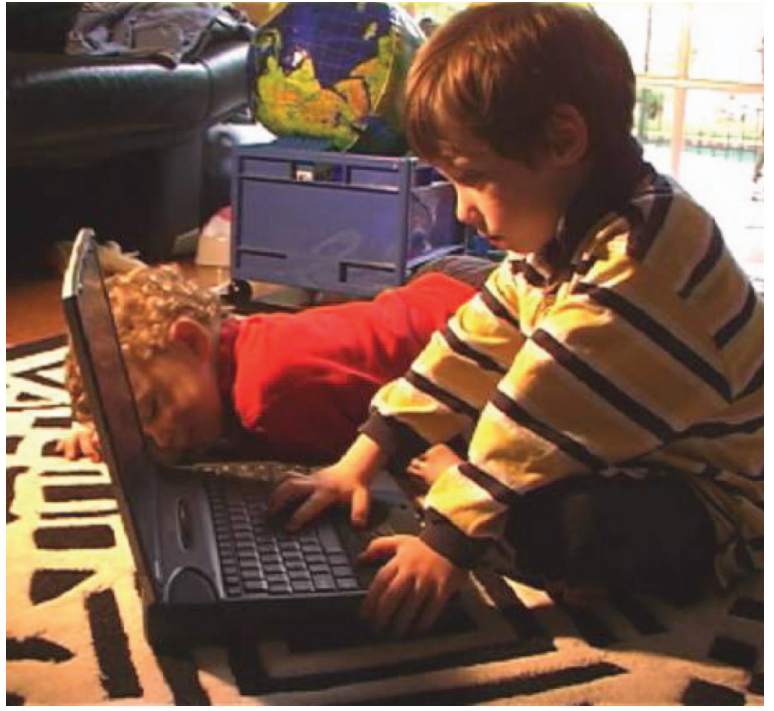

Figure 3. Use of computers at home.

Children tend to use computers more at home than at school (Moseley et al. 2001, Kerawalla and Crook 2002, Kent and Facer 2004). Access is sometimes shared at school but is often alone at home (Roberts et al. 1999, Kerawalla and Crook 2002, Attewell et al. 2003). A total of $31 \%$ of US children aged $8-18$ years have a desktop computer in their bedroom and $12 \%$ have their own laptop computer (Roberts et al. 2005). These children spent twice as much time on a computer (90 vs. $47 \mathrm{~min}$ ) compared to those who did not have their own computer.

\subsection{Influence of technology on exposure}

With the increasing portability of computers and the development of wireless Internet connectivity, computers are starting to be used more at locations other than school and home. Cyber cafes or Internet bars, which enable computer users to play games alongside their friends rather than alone at home, are popular with Hong Kong teenagers (Szeto 2003). In total, 11\% of students from Forms 4-7 reported spending between 1 and $7 \mathrm{~h}$ per week in these locations and Szeto reports that similar venues are popular in other Asian countries as well.

Technological advancements have also led to the miniaturisation of computer hardware. Laptop, tablet and palmtop computers are now available in addition to the traditional desktop PC. Smart phones and personal digital assistants also enable portable Internet connectivity. Given the differences in screen size, input devices and configuration, the smaller, portable computers obviously have different implications for posture and any associated musculoskeletal stress, so will not be addressed specifically in the current guidelines. Laptop and tablet computers, however, are often used with an external keyboard and mouse and can be used in a similar posture to desktop computers, although they may also be used in postures other than desk sitting (Harris and Straker 2000, Sommerich et al. 2007).

\subsection{Influence of individual characteristics on exposure}

Tasks performed on computers vary with age, with increasing use for school-related work and a reduction in leisure and computer game activities for older children (Kent and Facer 2004, Roberts et al. 2005, Australian Bureau of Statistics 2006).

There are also some gender differences in computer task preference. Studies consistently show more game playing by boys (Ho and Lee 2001, Kent and Facer 2004, Punamäki et al. 2007). Girls tend to have a greater communication component and this is consistent with a higher ownership and greater daily usage of mobile phones by girls (Punamäki et al. 2007).

In addition to the age and gender differences, there are also cultural differences in attitudes towards and methods of interacting with computers, including browsing websites, using search engines and menus and communicating online (see review by Yan and Fischer 2004).

In summary, many children have substantial exposure to computers and use them for a variety of tasks in a variety of environments using a variety of technology.

\section{Computer use has potentially positive and negative} impacts on child development

\subsection{Potential for positive effects}

Computer technology is likely to play an everincreasing role in the lives of children and adolescents. This technology provides positive benefits, which encompass the potential for increased learning opportunities, rapid access to vast stores of information, communication with family and friends, access to an environment where physical attributes or disabilities can be of minimal impact and training of fine motor and visual skills. This section and section 3.2 review the available evidence on the effects of computer use on children. Although the review was undertaken in a structured manner, the range of study types made use of a systematic review instrument unwieldy.

\subsubsection{Cognitive development}

The effect of computers on learning and academic achievement is of great interest to parents, educators 
and administrators, concerned that children should not be left behind in the new 'information age'. Whilst the evidence is mixed, it does appear that computers can enhance academic performance. Home computer ownership has been shown to be positively related to performance on standardised academic tests (Rocheleau 1995, Attewell and Battle 1999, Harrison et al. 2002, Attewell et al. 2003, Borzekowski and Robinson 2005). Effect sizes vary, with Harrison et al. (2002) and Attewell et al. (2003) describing modest but positive effects, while Borzekowski and Robinson (2005) report a more substantial effect. This relationship is clearly multifactorial and is likely to be affected by the type of computer use, adult guidance and many other factors. For example, Attewell et al. (2003) found that home computer use of less than $8 \mathrm{~h}$ per week was associated with better academic performance. However, children who used a computer for more than $8 \mathrm{~h}$ per week did not differ academically from non-users. Playing of computer and video games has been associated with poorer academic achievement (Moseley et al. 2001, Roberts et al. 2005, Anand 2007).

One area in which computers have been a benefit to learning is that of health education. A comprehensive review by Lewis (2003) highlighted the efficacy of computer-based education for improving the knowledge and health outcomes of children with conditions such as asthma and diabetes and this approach has also been effective for cystic fibrosis (Davis et al. 2004).

With regard to sex education, a survey of 760 Canadian university students (Boies 2002) revealed that more than $20 \%$ had received their first sexual education material via the Internet. The anonymity of the Internet may provide the opportunity to seek information that a child or teenager would be hesitant to ask in person. There is some suggestion that the information obtained online by adolescent girls may actually encourage better sexual decision making (Subrahmanyam et al. 2000).

Used wisely, it does appear that computers can be of benefit to learning. Wartella and Jennings (2000) suggest that the increased interactivity of new information technology compared to older media provides an opportunity for enriched learning. However, the development of strategies for integrating computer technology into classroom teaching practice is in its infancy (Shields and Behrman 2000). Computer guidelines need to encourage cognitive development.

\subsubsection{Social development}

The computer can become a centre for the social interaction of children with their peers and family. In the school environment, computers have been found to lead to group interaction and cooperation and to facilitate communication (Orleans and Laney 2000, Heft and Swaminathan 2002). In a study of home and school computer use by more than 1800 children from the UK, Kent and Facer (2004) reported that children at school frequently worked in lessons where they were surrounded by their peers and offered and received help and guidance from these peers. At home, the relatively recent phenomenon of instant messaging was used to extend social interactions, with many children messaging continuously throughout the entire session of computer use. Instant messaging was used to chat, make social arrangements and discuss homework. It therefore appears that although the majority of children using a home computer do so with little adult accompaniment or supervision (Roberts et al. 1999, Attewell et al. 2003), children are adept at using the networked nature of the modern computer environment to extend rather than limit social interactions.

Ho and Lee (2001) found that male computer users who spent more time on computer-mediated communication, surfing the Internet and doing homework tended to have greater perceived social support. Rocheleau (1995) also reported that heavier computer users were similar to other students in social activities. Research relating to computer users who primarily play games has elicited mixed results. Orleans and Laney (2000) found that networked computer games provided a positive socialisation for teenagers; however, Hong Kong teenagers (males) who used the computer primarily for playing games tended to have lower perceived social support (Ho and Lee 2001). A review of the effects of computer game playing by Subrahmanyam et al. (2000) concluded that moderate game playing appeared benign in terms of social skills and relationships, with some studies reporting mildly positive effects and others finding no difference in social skills between game players and non-game players.

The computer can also be used as an 'equaliser' in social contexts. Computers can be used in the classroom to help children with physical or learning special needs keep up with their peers (Hasselbring and Williams Glaser 2000). Online social network sites for chronically ill children have also been effective in reducing anxiety and loneliness (Battles and Wiener 2002) and promote socialisation of children with others who have the same illness (e.g. www. starbrightworld.org). The filtered nature of computer networked social interactions can also be beneficial. Wartella et al. (2000) suggests: 'The emphasis on shared interests rather than social or physical characteristics can be empowering for all people, and especially for members of disadvantaged social groups, those who may be geographically isolated, or physically disabled'. Computer guidelines need to encourage social development. 


\subsubsection{Visual and motor development}

According to Subrahmanyam et al. (2000), computer applications, and especially computer games, tend to be based on visual rather than verbal information processing. Playing these games can increase children's visual processing capacity in areas, which are components of the particular game. Such improved visual processing may have applications for rehabilitation (Green and Bavelier 2007).

Fine motor skills can also be improved with the playing of electronic games. Yuji (1996) reported evidence that electronic games improved children's fine motor performance. A review by Whitcomb (1990) found that electronic game playing led to enhanced eye-hand coordination, dexterity and fine motor ability and increased reaction and movement speeds in elderly subjects. Rosser et al. (2007) found a doseresponse relationship between video game experience and laparoscopic surgery training performance (both speed and accuracy). Computer-based games have been effective in the rehabilitation of gross motor skills in individuals following a stroke (Sveistrup 2004) and for children with cerebral palsy (Reid 2002). Computer guidelines need to encourage physical development.

\subsection{Potential for negative effects}

Concerns about the safety of children using computers include physical effects (musculoskeletal discomfort, visual problems and sedentariness) together with content and online interaction concerns (inappropriate content, cyber-bullying, financial security and the potential for sexual abuse) and personal social impact (withdrawal, addictive use of computers).

\subsubsection{Child safety}

The relative anonymity of computer use makes it possible for users to portray themselves inaccurately and gain the trust of children online. There have been instances where adults have made contact with children initially via the Internet, then travelled to meet them in person. There are also current cases whereby social networking sites popular with children have been subject to lawsuits because of failure to protect children by not verifying the ages of participants. There is some pressure to bring in credit card checking as verification of identity, but it is not a simple issue to decide who has the ultimate responsibility for protecting children and how this can best be achieved. Recent controversies also include privacy issues, such as the difficulty of removing personal accounts from the network once an individual has 'unsubscribed' and the tracking of purchases outside the network system by network members. The complexity of these privacy issues may be difficult for more trusting children and teenagers to understand; hence, they may be at higher risk than adults.

Similarly, children may be more likely than adults to provide financial or other confidential information online. Increasingly sophisticated financial scams occur via email and the Internet and children may inadvertently put family security at risk if they are unaware of the tactics employed by these criminals. Some of these scams are directly targeted towards children. A recent case involved the hacking (and 'phishing') of a profile page for a music celebrity on a social networking site highly popular with teens. Clicking anywhere other than specifically on link buttons led to downloading of 'rootkit' software, which would allow future stealthy access to the infected computer. Whilst law enforcement personnel and technology companies attempt to develop protection against these activities, it has been recommended that parents and other caregivers assume responsibility and provide education to the children in their care (McColgan and Giardino 2005).

In recent years, considerable resources have been devoted to children's safety during Internet use - for example, the Australian Federal Government recently allocated \$189 million (Australian) to create a programme entitled 'NetAlert - Protecting Australian Families Online' (www.netalert.gov.au). This programme includes education, free filtering software and increased funding to police personnel dedicated to combating online child sexual exploitation. The US Federal Bureau of Investigation have also published guidelines for children's safety during Internet use (http://www.fbi.gov/publications/pguide/pguidee.htm) and similar guidelines and programs have been implemented by many other countries.

Other safety concerns include electrical hazards and cord tripping or choking hazards. There have also been reports of children being attacked to rob them of a portable computer.

Aside from child safety, there are also important equipment safety considerations including protection of intentional or unintentional damage to hardware and software.

Computer use guidelines therefore need to encompass child and technology safety. Child safety is clearly of paramount importance and the other consequences of computer use may seem less important. However, the current generation of children is starting to use computers prior to commencing school. By the time they enter the workforce as young adults, these individuals will have been using computers, many of them for several hours per day, for more than a decade, while their 
minds and bodies are still developing. Thus, the impacts on cognitive, social and physical development are important.

\subsubsection{Inappropriate cognitive development}

A US study of 1500 Internet users aged 10-17 years found that $42 \%$ had been exposed to pornography on their computer and two-thirds of this was unwanted exposure (Wolak et al. 2007). The use of filtering software and attendance at an Internet safety course presented by a police officer or similar offered some protection. Talking about online pornography to a parent or an adult at school was actually associated with higher odds of exposure; however, this may have been related to discussions occurring as a consequence of the initial exposure. The use of file-sharing software also increased the risk of exposure, while the amount of Internet use was not related to the risk.

Some researchers have attempted to mitigate concerns by comparing current computer issues with historical (very similar) concerns relating to the introduction of earlier forms of media such as radio, television and films (e.g. Arrback 1997, Wartella and Jennings 2000). However, the sheer scale of accessibility may justify a greater level of concern with computers. It is much simpler and less costly to access inappropriate content online than in physical form, such as print or DVD, and, as described previously, a significant amount of exposure is unsolicited. Additionally, whilst television is subject to rating of its sexual content, the Internet is not (Escobar-Chaves et al. 2005).

Sexual content is not the only form of inappropriate content that is easily available to children. A simple search for topics ranging from how to make a weapon or bomb to how to commit suicide will elicit thousands of 'hits'. The US school safety organisation 'Safe Havens International' has described being able to easily download bomb-making content through computers located in school media centres, including a 200 page manual containing instructions for the manufacture of napalm and car bombs (www.safehavensinternational.org). The US Department of Justice (1997) concluded that information describing how to make bombs was 'literally at the fingertips of anyone with access to a home computer equipped with a modem'. Information on suicide techniques and how to cheat on exams is similarly accessible. A search for 'how to cheat' on the video-sharing website YouTube.com returns more than 4000 video clips, as well as suggestions for related search terms.

Computer use guidelines therefore need to minimise the risk from inappropriate content likely to harm cognitive development.

\subsubsection{Inappropriate social development}

A review by Browne and Hamilton-Giachritsis (2005) of the effects of violent media on children and adolescents found a small but significant association between aggression and exposure to media violence. The evidence was more consistent for younger children and in the short term. Funk (2005) also reported evidence for a decrease in empathy in children who had a preference for violent video games. Some individuals appeared to be more susceptible, with personality and lifestyle variables also influential.

According to Wartella et al. (2000), the interactive nature of computer and video games makes them particularly powerful media experiences for children. Children can select not only the character but often particular traits that are assigned to that character. Players receive rewards such as points or further access in the game for successful aggressive acts and choices. These authors caution that there is only recent and limited evidence that this reinforcement might teach aggressive behaviour. The overall body of research, however, does suggest that there is enough evidence to warrant concern, particularly for some individuals.

A further concern relating to social development and new technology is the phenomenon of cyberbullying (bullying using new technology such as mobile phones, websites and email). Research is in its infancy but this may be a particularly damaging form of bullying because there is 'a potential for a much wider audience to be aware of the incident than in schoolyard bullying' (Campbell 2005). The simplicity of transmission of electronic data including images and text may perpetuate the original incident.

The ease with which data can be published and transmitted electronically also facilitates a greater forum for those who propagate racism and intolerance. Whilst adults should have the experience to make objective assessments of information that is available online, children may be unable to assess the motives behind such information (or misinformation) and may believe that if the content has been published online it must be correct. Children can have difficulty distinguishing between fantasy and reality, with reports of children believing that characters in computer games are 'a little alive' (Turkle 1995).

For most computer and Internet users, the social consequences of computer use appear to be positive. However, a small proportion of users show behaviours that could be classified as dependent or addictive and may lead to social impairment, increased loneliness and sleep disruption (Nalwa and Anand 2003). The proportion of users classed in this category depends upon the selection criteria; however, a Medline search for "Internet addiction" returns more than 700 listings. 
The Chinese Government considers Internet addiction to be problematic enough for its citizens that in 2007 they mandated that computer companies install antiaddiction software into their games. Penalties such as loss of points or game shutdown occur if warnings about continuous play duration are ignored.

The HomeNet project was an interesting study of 93 North American families with new access to the Internet, conducted between 1995 and 1998 (Subrahmanyam et al. 2000). Children and adolescents were heavier users of the Internet than were their parents. In the first year of computer and Internet access, greater use of the Internet was associated with declines in social well-being, including increased loneliness and depression. After the first year, there were smaller declines or actual improvements in psychological well-being. Possible reasons for this change included the development of the Internet environment itself over time (including the uptake of instant messaging), a shift towards communicating more with those who had stronger ties with the individual and technology becoming more accessible, so that more of their friends and family were available online.

Computer use guidelines need to minimise the risk from content likely to harm positive social development.

\subsubsection{Displacement of other activities}

Given the increasing use of computers by children and teenagers, there is concern that physical activity will decline further and thereby impact future health, particularly in view of the increased obesity of current generations - as appears to be happening in adults (Straker and Mathiassen 2009). Evidence for the displacement of moderate to vigorous physical activity by computer use is mixed. Straker et al. (2006c) found a negative relationship between computer use and vigorous physical activity on weekends in 1600 young Australian children. Amongst older (approximately 11-17 years) children from Hong Kong, computer users exercised more frequently than non-users (Ho and Lee 2001). Vandewater et al. (2004) found a weak negative relationship between computer use and moderate physical activity, but Burke et al. (2006) found no relationship. Attewell et al. (2003) examined this issue at greater depth and found that children who spent less than $8 \mathrm{~h}$ per week using the computer did not differ from non-users in relation to time spent playing sports or watching TV. In contrast, children who were heavy users ( 8 or more hours per week) spent $3 \mathrm{~h}$ less per week on sport and outdoor activities compared to children who did not use computers at all.

Displacement of physical activity by television viewing has been more extensively studied. In a review of 39 studies of children and youth, Marshall et al.
(2004) concluded that the relationship between TV viewing and physical activity was small $(\mathrm{r}=-0.129)$ and negative and this has been supported by similar reviews. Motl et al. (2006) recently reported a stronger relationship between naturally occurring fluctuations in TV viewing and physical activity. However, only one randomised, controlled trial (Robinson 1999) has evaluated the effect of an intervention to reduce television viewing on physical activity. Whilst the study was able to demonstrate a reduction in body fatness, there was no effect on overall physical activity and it has not been replicated.

The relationship between computer use and body mass status has also generated conflicting results. Kautiainen et al. (2005) conducted a self-report survey of Finnish adolescents aged 14, 16 and 18 years. There was an increased odds ratio for being overweight for girls who used the computer for more than $1 \mathrm{~h}$ per day, with a similar but non-significant trend for boys. When analysed by age, the result was statistically significant for 16-year-old girls only. Janssen et al. (2005) found no association between obesity of adolescents from 34 countries and time spent on the computer but overweight children spent more time watching television. Lajunen et al. (2007) reported that having a home computer was associated with a higher risk of overweight amongst 17-year-old Finnish teens but having a computer with an Internet connection was not associated with weight status. Those who spent more time on the computer had a greater risk of being overweight. Other studies have not shown any association between weight status and computer use (Wake et al. 2003, Burke et al. 2006).

Studies of food advertising on children's television are abundant (see Kaiser Family Foundation 2004) and this is one of the theorised pathways for a link between television viewing and fatness. Some countries have made it more difficult for companies to market food to children via television; hence, companies are now turning their attention to Internet advertising. Many confectionery, cereal and 'fast-food' companies are now including product-related games on their websites in order to engage children and gain brand awareness. Whether this 'hidden' advertising will have a similar effect to television advertising is yet to be determined.

Newer forms of input for computer and video games offer some promise for decreasing the sedentary nature of computer and video games. Devices such as the EyeToy (Sony Computer Entertainment,) Wii (Nintendo) and dance mats require gross motor activity to progress through computerised games. These active input devices have resulted in increases in energy expenditure, heart rate and ventilation volume when compared to traditional interfaces 
(Lanningham-Foster et al. 2006, Graves et al. 2007, Maddison et al. 2007, Straker and Abbott 2007).

Displacement of sleep time has also been associated with computer use. Adolescents commonly use media, including books, music, computer games and television, as a sleep aid (Eggermont and van den Bulck 2006). However, with the exception of books, this practice was actually associated with less sleep and greater tiredness. Similarly, Punamäki et al. (2007) reported an association between intensive use of information technology and poorer sleeping habits, particularly during early adolescence. For boys, this sleep disruption was related to digital games and Internet use, whilst for girls mobile phone use was a greater risk factor.

Computer use guidelines need to minimise the risk of adverse displacement of physical activity.

\subsubsection{Vision problems}

Opinion is somewhat divided as to whether viewing a computer screen is more visually demanding than reading from printed paper (see Burns 1995, Yan et al. 2007). Concerns relating to children's viewing of computer screens have prompted organisations such as the American Optometric Association to publish recommendations for 'visually friendly' computer use. However, surprisingly little scientific attention has been devoted to this issue in children. A preliminary field study of Scottish schoolchildren showed that those who did use a computer were 1.4 times more likely to fail a visual acuity screening test; however, there was no dose-response effect (Kerr and Tappin 2002). Extensive viewing of near objects may strain the visual system and result in structural change of the orbit, in particular refractive changes causing myopia. A study of children in Singapore found no evidence of refractive changes associated with increased computer viewing (Tan et al. 2000). In adults, a computer task was shown to reduce eye-blink frequency by $69 \%$ compared to passive watching of a video and the blink frequency was also affected by the viewing angle (Skotte et al. 2007). Computer use guidelines need to minimise the risk of adverse visual effects.

\subsubsection{Musculoskeletal problems}

Pain and musculoskeletal discomfort have been associated with computer use by adult populations (Bergqvist et al. 1995, Marcus et al. 2002) and there are indications that this may also be an issue for college students (Katz et al. 2000, Hamilton et al. 2005, Menéndez et al. 2007) and younger children (Harris and Straker 2000, Jacobs and Baker 2002, Williams 2002, Szeto 2003, Straker et al. 2006a). Hakala et al.
(2006) conducted a survey study of 6003 Finnish children aged 14, 16 and 18 years. A dose-response relationship was reported for computer use and neck/ shoulder pain. However, there was a fairly high threshold ( $>42$ h weekly or $>2-3$ h daily) for the occurrence of pain. Computer workstations can influence gravitational moments, muscle capacity and relative strain around the neck (Straker et al. in press). Computer use has also been related to habitual posture in adolescents (Straker et al. 2007) and changes in classroom furniture have been associated with posture changes (Koskelo et al. 2007).

Some schools have adopted mobile computers such as laptops and notebooks, which travel with the child to and from school each day and are used in both locations. Children's use of these portable computers has been associated with musculoskeletal discomfort (Harris and Straker 2000, Sommerich et al. 2007). Computer-related discomfort in childhood and adolescence may be of particular concern as the musculoskeletal system and posture are still developing. There is, therefore, the potential for any problems during childhood to become an ongoing issue in adulthood. The widespread adoption of computer technology by children is by definition a recent phenomenon so it is unknown how any problems will track into adulthood. However, there is some longitudinal evidence that low back pain during childhood is a risk factor for low back pain in adulthood (Harreby et al. 1995). Computer use guidelines need to minimise the risk of adverse musculoskeletal effects.

In summary, reviews of the effects of ICT for children confirm that a great number of children are using computers at home as well as at school, with much of the home use taking place in the absence of an adult. Exposure to the violent content found in many computer games can increase aggression, at least in the short term. Internet use by teenagers and children is providing access to sexual content and pornography. There is also emerging cross-sectional evidence that musculoskeletal symptoms and vision problems can result from computer use. Valuable aspects of computers include communication capabilities and access to vast sources of information. Perhaps the most notable feature of research is how much is still unknown, although this is unsurprising given the extremely rapid changes in technology and its use.

Much more comprehensive research is available concerning television; however, computer use is both similar and different. Existing controls related to television include rating of content and scheduled programming, whereby certain content can only be shown during certain hours. By its nature, access to Internet content may be more difficult to 
regulate - content is available at any time of the day or night and uploading content to a website is accessible to almost anyone.

Children are likely to be particularly at risk because of their immaturity - young children have a blurred line between fantasy and reality, lack of contextual exposure to evaluate the 'truth' of content, motives behind advertising, etc. In a 10-year review of the effects of media on children, Villani (2001) concluded 'The cost of ignoring the impact of the media on children and adolescents will be enormous, both in absolute dollars and in the immeasurable cost of human pain and suffering'.

\section{Child specific guidelines are needed}

\subsection{Adult guidelines for safe and appropriate} computer interaction have been developed nationally and internationally

Concerns about the physical effects of computers on adults resulted in the development of international and national standards and guidelines including the International ISO 9241, European Community Council Directive 90/270/EEC, North American BSR/HFES 100 and Australian National Code of Practice for the Prevention of Occupational Overuse Syndrome. Other guidelines that have been developed for adults include workplace guidelines for appropriate task and content and government guidelines for appropriate content (for example, the illegality of production, distribution and possession of child pornographic images).

Guidelines for children's use of computer are fewer and it is arguable that there should be guidelines to assist all those concerned with optimising the interaction of children with computers.

\subsection{Child computer tasks and patterns of use are different}

Adult guidelines are oriented towards work tasks and the work environment but computing tasks performed by children may be significantly different from these adult work tasks. Game playing consistently emerges as the most common use of computer time in studies of children's computer tasks (Shields and Behrman 2000, Wartella et al. 2000, Roberts et al. 2005). Instant messaging is another activity that is highly popular with children aged 8-18 years (Roberts et al. 2005). Whilst it is entirely possible that adults using computers at home engage in these activities, it is unlikely that they form the predominant component of the average adult's computing day. Children's school computing tasks are also likely to differ from adults' work tasks - for example, they may frequently have to look at a teacher and/or display board as well as the computer. Collaboration between children at nearby workstations and sharing workstations between children can also be a component of school computer use (Kent and Facer 2004).

'Media multitasking' has emerged as a characteristic behaviour among children using computers (Kent and Facer 2004, Roberts et al. 2005, Foehr 2006). In a study of more than 1000 US children aged 8-18 years (Foehr 2006), one-third of children who used a computer at home were also listening to music, using a telephone, reading or using some other form of media. There has sometimes been a tendency to assume that results of television research can be generalised to computer use (particularly in relation to displacement of other activities); however,

multitasking is a further difference between the two. Television viewing was the least 'multitasked' form of media, while computer use was the most multitasked. Keeping an instant messaging program open throughout all other computer use was also shown to be common among British children (Kent and Facer 2004).

\subsection{Child computer use environments are different}

Whilst adults are likely to have their own personal workspace, chair and computer at work, children often share computers with one or more other individuals at school (Sotoyama et al. 2002, Breen et al. 2007). In addition, there is ample evidence to show that many children are using school computers at workstations that are unsuitable for their morphology (Oates et al. 1998, Zandvliet and Straker 2001, Sotoyama et al. 2002, Dockrell et al. 2007). The physical effects of this discrepancy may currently be mitigated by the relatively short duration of use at school (Oates et al. 1998, Sotoyama et al. 2002). However, neck, upper back and lower back pain have all been associated with school furniture features (Murphy et al. 2007). About 10 years ago, Laeser et al. (1998) lamented the lack of comprehensive standards from which educational administrators and product designers could base decisions regarding computer environments for children; unfortunately, this situation appears to have changed little in the subsequent decade. Compounding the problem, schools tend to place more emphasis on the quality of computer equipment rather than the workstation environment (Zandvliet and Straker 2001), presumably as a result of budget considerations. It has been argued that schools provide an opportunity for educating children about computer use (Pollock and Straker 2008).

At home, most children use a computer while sitting at a desk but other locations such as a kitchen or dining table or sitting at a sofa are also used 
(Ramos et al. 2005). With portable computers such as laptops and notebooks, a substantial proportion (35$66 \%$ ) of use takes place away from a desk or table (Harris and Straker 2000, Sommerich et al. 2007). In countries with a high population density, space limitations may dictate the location of the home computer (Szeto 2003). Although it is assumed that much of children's home computer use occurs using furniture and workstations designed for adults, there is very limited actual evidence to support this assumption. Jacobs et al. (2003) assessed home computer workstations for a sample of US children aged 12-15 years and examined the association between workstation parameters and musculoskeletal pain. It can be inferred from this study that adult-sized furniture was used by several of the children, as there was an association between the occurrence of pain and the student sitting without the feet flat on the floor. No other studies of home workstation ergonomics for children could be located. This is clearly an area of concern, as children use computers for longer durations at home compared to school (Moseley et al. 2001, Kerawalla and Crook 2002, Kent and Facer 2004).

\subsection{Children are different to adults physically, cognitively, socially}

Children's motor skill development has been shown to affect their ability to operate input devices at various ages, with younger children having greater difficulty operating a mouse or joystick compared to a touchscreen or key push (Scaife and Bond 1991). Mastery of all four input devices occurred at about 8 years of age; however, there was substantial individual variation at each age. Adult and child motor skills in using input devices may therefore be different.

Effects of size differences between adults and children when using a computer have been studied in 5- to 8-year-old children and their same-sex parent by Blackstone et al. (2008). Despite adjusting the set-up to allow for their smaller size, children worked with substantially greater ulnar deviation and less wrist extension than their parents. The children applied twice the relative force to operate the mouse buttons. Proportional head mass is also a developmental difference between adults and children and it has been suggested that this may affect the physical ramifications for children viewing different display heights (Straker et al. 2008a).

Yan and Fischer (2004) reviewed the literature concerning cognitive and social differences in learning to use computers and concluded that very little was known about developmental differences between children and adults in this context. It is reasonable to assume, however, that social and cognitive immaturity may offer less protection for children compared to adults when interacting with the computer. For example, the American Optometric Association (undated) suggests that absorption in a task and lack of knowledge may lead children to ignore visual symptoms related to computer use because they believe everyone sees the way that they do. It has also been argued that the relationships between risk factors and musculoskeletal outcomes may also be different for children than adults (Harris et al. 2005).

\subsection{Children are growing and developing so there may be a greater potential to be affected}

Heavy use of computers while children are still developing may incur different problems from adults. In the online CybErg discussion hosted by Straker et al. (2006a) as a forum for children's guideline development, development of the cervical spine, growth plates and the fact that children were in a 'physical building' rather then 'physical support' phase were all proposed as relevant adult-child differences. In addition, there may be more potential to change in a developing individual, both in terms of physical structure and habits and the mental approach to computers (Straker et al. 2006b). Cognitive development may also affect the consequences of exposure to certain forms of media content. One of the concerns relating to violent video game use is the relatively late development of the prefrontal cortex (Funk 2005). After adolescence, the preference for violent video game content diminishes.

\subsection{Child computer use may impact on adult risk/ computer use}

There is concern that musculoskeletal problems in childhood could carry forward to adulthood. The development group for the European guidelines for prevention in low back pain (Burton et al. 2006) highlighted the importance of researching such tracking into adulthood for low back pain and proposed that: 'From a physiological point of view, poor lifestyle habits and prolonged static sitting during school age on unadjusted furniture may play a role in the origin of LBP .... These authors also recommended that study with a follow-up into adulthood was necessary to determine whether loads incurred in childhood due to unadjusted furniture or heavy book-bags could affect the incidence of adult pain. There is some longitudinal evidence to suggest that low back pain during childhood is a risk factor for low back pain in adulthood (Harreby et al. 1995). Whilst computer-related musculoskeletal discomfort is 
also prevalent higher up in the spinal column and in the upper extremities (Hünting et al. 1981, Faucett and Rempel 1994, Bergqvist et al. 1995, Sillanpää et al. 2003), similar principles are likely to apply.

\subsection{Available child guidelines}

Existing guidelines relating to children and computer use were reviewed by Straker et al. (2006b). These guidelines were found to be limited, particularly in the area of physical interaction. Available guidelines originated from sources varying from technology companies and those with a commercial interest, through to government departments to self-help and community groups, such as parenting support groups. Many of them appeared to be based on 'common sense' rather than actual evidence and these 'common sense' guidelines can be conflicting - for example, with regard to recommendations for or against drop-down keyboard trays. There may also be trade-offs between the costs and benefits of ICT use (Straker and Pollock 2005); for example, better learning outcomes at the cost of poorer skeletal development. Guidelines should assist users to balance these outcomes.

\subsection{Pathway to develop evidence-based child specific guidelines}

A pathway for the development and implementation of evidence-based guidelines for children using computers has been detailed by Straker and Pollock (2005). This pathway included peer review of research and guidelines, as well as review by target audiences. Widespread promulgation was recommended along with specific education targeted towards children, responsible adults, education authorities and the ICT industry. It was suggested that continued monitoring of guidelines over time and amongst different populations would be essential, particularly in view of the rapidly changing nature of ICT hardware and software. It was also suggested that guidelines should aim to be based on general principles rather than specific technology, to allow for expected technological developments.

\subsection{Progress towards evidence-based child specific guidelines}

Activities that have been performed to date have included review of available guidelines, review of scientific literature, conduct of research to fill knowledge gaps and promotion of international debate and review.

Internet sites relating to child computer use guidelines were identified (Straker et al. 2006b). Four basic types were found: 1) fraud protection; 2) social protection; 3) education/software selection; 4) workstation set-up. These guidelines were produced by a range of authors including technology companies, government departments, professional organisations, individuals with an interest in the area and self-help and community groups.

Scientific literature has been searched using electronic databases and reference lists of found articles. Information related to computer exposure has been summarised in the current paper and information related to specific guidelines will be reviewed in specific guideline papers.

Specific research has been conducted to fill identified gaps in knowledge. The influence of display height (Straker et al. 2008a) and forearm support (Straker et al. in press) on posture, muscle activity and their exposure variability (Straker et al. 2009b) was investigated in children. Variability of adult posture and muscle activity was also compared to that of children aged 10-12 years and 5-6 years (Maslen and Straker 2009). An evaluation of tablet computers has also been conducted (Straker et al. 2008b).

International debate has been facilitated with a keynote presentation at the International Ergonomics Association Congress in 2003 (Straker and Pollock 2003), with publication in Ergonomics (Straker and Pollock 2005) and the subsequent presentation and discussion forum at the CybErg 2005 international conference (Straker et al. 2005), with publication of the paper and discussion in the International Journal of Industrial Ergonomics (Straker et al. 2006a,b). The CybErg 2005 discussion included the need for a shared conceptual model, facilitating cognitive development, task variety, reasonable postures during sedentary tasks, touch typing and responding to discomfort. The purpose of this peer review was to identify invalid or obsolete assumptions and guidelines and identify gaps in the available evidence.

\section{Evidence-based guidelines}

Based on the activities to date, it was clear that there was a need for child-specific evidence-based guidelines for wise use of computers. It was also clear that there was a body of knowledge available to inform these guidelines, but that this evidence base was limited. However, the present authors thought it was imperative that current knowledge was published and promulgated as soon as possible, given the extent of computer use by children. However, it is also important to realise that this area is still very much under-researched, as an inevitable consequence of the pace of social and technological change and the wide spectrum of physical, cognitive and social ramifications of computer use. 
Table 1. Principles of wise use of computers by children.

\begin{tabular}{|c|c|}
\hline No. & Principle \\
\hline 1 & $\begin{array}{l}\text { Ensure computer literacy } \\
\text { Children have a right to know about the positive and negative aspects of computer use. } \\
\text { Teach children (and those around them, responsible for them, contributing to child-computer interaction) appropriate } \\
\text { skills for wise computer use. } \\
\text { Wise use of computers requires educated children. }\end{array}$ \\
\hline 2 & $\begin{array}{l}\text { Ensure technology safety } \\
\text { The computer technology needs to be adequately protected against unintentional hardware or software damage by a child } \\
\text { user. The computer also needs to be protected against intentional damage by an upset child, bully, hacker or virus/worm } \\
\text { program. } \\
\text { Wise use of computers needs to ensure appropriate protection of technology. }\end{array}$ \\
\hline 3 & $\begin{array}{l}\text { Ensure personal safety and privacy } \\
\text { The child needs to be kept safe from electrical hazards, cord tripping/choking hazards and violent theft. The child needs } \\
\text { to be kept safe from personal identify theft, financial fraud and inappropriate financial transactions. The child needs } \\
\text { to be kept from participating in illegal activities such as music and video piracy and other unethical or undesirable } \\
\text { behaviours such as plagiarism and gambling. The child also needs to be kept safe from people with paedophilic or other } \\
\text { abuse intent. } \\
\text { Wise use of computers needs to ensure adequate safety of each child. }\end{array}$ \\
\hline 4 & $\begin{array}{l}\text { Encourage appropriate social development } \\
\text { Computer use provides opportunities for positive social experience. 'Netiquette' guidelines encourage children to learn and } \\
\text { use socially acceptable rules of social interaction. Computer use allows children to find new friends and break out of } \\
\text { current constraints on their interactions, such as their physical appearance. However, computer interaction can expose } \\
\text { children to observation of and participation in violence, religious/cultural/gender intolerance, bullying and pornography. } \\
\text { Children need to be kept from obsessive 'addictive' computer interaction. } \\
\text { Wise use of computers needs to protect from negative social influences and promote positive social development. }\end{array}$ \\
\hline 5 & $\begin{array}{l}\text { Facilitate appropriate cognitive development } \\
\text { Computer use provides opportunities for positive cognitive development in the areas of literacy, numeracy, problem solving } \\
\text { and subject-specific content through the use of age appropriate software and content. However, computer use, } \\
\text { particularly with Internet access, provides opportunities for children to access potentially inappropriate content such as } \\
\text { drug use, bomb making and suicide methods. } \\
\text { Wise use of computers needs to protect from negative content and promote positive cognitive development. }\end{array}$ \\
\hline 6 & $\begin{array}{l}\text { Facilitate appropriate physical development } \\
\text { Desktop and laptop computer use provides opportunities for fine motor skill development. However, computer use may } \\
\text { also result in visual strain, poor postures, prolonged postures and actions, displacement of physical activity and loss of } \\
\text { gross motor learning experiences. } \\
\text { Wise use of computers needs to protect from potentially damaging physical stresses and promote positive physical } \\
\text { development. }\end{array}$ \\
\hline
\end{tabular}

Given the extensive knowledge available, the present authors propose to present the guidelines in several parts: this initial paper with the general principles to be followed by papers reviewing the specific evidence for specific principles. The principles are an evolution of the draft guidelines previously reported (Straker and Pollock 2005, Straker et al. 2006b) and discussed at international conferences. The principles provide overarching guidance, but may be difficult to operationalise. The subsequent more detailed papers will provide more easily operationalised content within this framework.

Table 1 presents six general principles for wise use of computers by children. Principle 1 enshrines the right to knowledge for children using computers. Principles 2 and 3 encompass technical and personal safety issues. These have been the focus of most guidelines to date (Straker et al. 2006b). Principles 4, 5 and 6 encompass the physical, cognitive and social development issues and will each be the focus of a subsequent paper.

It is hoped that these guidelines will provide both useful and current information for educators, parents, workstation and hardware designers and children themselves. It is also an aim that the information contained herein provides a stimulus for further research into this important area.

\section{References}

American Optometric Association, undated. Impact of computer use on children's vision [online]. Available from: www.aoa.org/x5379.xml [Accessed 31 March 2008].

Anand, V., 2007. A study of time management: The correlation between video game usage and academic performance markers. CyberPsychology and Behaviour, $10,552-559$. 
Arrback, G., 1997. The most challenging issues for media regulators today [online]. Available from: www.aic.gov. $\mathrm{au} /$ conferences/violence/arrback.pdf [Accessed 2 April 2008].

Attewell, P. and Battle, J., 1999. Home computers and school performance. The Information Society, 15, 1-10.

Attewell, P., Suazo-Garcia, B., and Battle, J., 2003. Computers and young children: Social benefit or social problem? Social Forces, 82, 277-296.

Australian Bureau of Statistics, 1998. Household use of information technology, Australia, Feb 1998 [online]. Report No. 8128.0, Available from: http://www.abs.gov. au/ausstats/ [Accessed 14 March 2008].

Australian Bureau of Statistics, 2006. Children's participation in cultural and leisure activities [online]. Report No. 4901.0, Available from: http://www.abs.gov.au/ausstats/ [Accessed 14 March 2008].

Battles, H.B. and Wiener, L.S., 2002. STARBRIGHT World: Effects of an electronic network on the social environment of children with life-threatening illnesses. Children's Health Care, 31, 47-68.

Bergqvist, U., et al., 1995. Musculoskeletal disorders among visual display terminal workers: individual, ergonomic and work organizational factors. Ergonomics, 38, 763-776.

Blackstone, J.M., et al., 2008. Physical exposure differences between children and adults when using standard and small computer input devices. Ergonomics, 81, 872-889.

Boies, S., 2002. University students' uses of and reactions to online sexual information and entertainment: Links to online and offline sexual behaviour. Canadian Journal of Human Sexuality, 11, 77-89.

Borzekowski, D.L.G. and Robinson, T.N., 2005. The remote, the mouse, and the No. 2 pencil: The household media environment and academic achievement among third grade students. Archives of Pediatric and Adolescent Medicine, 159, 607-613.

Breen, R., et al., 2007. An investigation of children's posture and discomfort during computer use. Ergonomics, 50, 1582-1592.

Browne, K.D. and Hamilton-Giachritsis, C., 2005. The influence of violent media on children and adolescents: a public health approach. Lancet, 365, 702-710.

Burke, V., et al., 2006. Television, computer use, physical activity, diet and fatness in Australian adolescents. International Journal of Pediatric Obesity, 1, 248255.

Burns, D.H., 1995. Characteristics of visual display units that may cause visual difficulties. Ophthalmic and Physiological Optics, 15, 99-104.

Burton, A.K., et al., 2006. European guidelines for prevention in low back pain. European Spine Journal, 15, S136-S168.

Campbell, M.A., 2005. Cyber bullying: An old problem in a new guise? Australian Journal of Guidance and Counselling, 15, 68-76.

Computer Industry Almanac, 2006. Worldwide Internet users top 1 billion in 2005 [online]. Available from: www.c-ia.com/pr0106.htm [Accessed 14 March 2008].

Davis, M., et al., 2004. Controlled evaluation of the STARBRIGHT CD-ROM program for children and adolescents with cystic fibrosis. Journal of Pediatric Psychology, 29, 259-267.

Dockrell, S., et al., 2007. School children's use of computers and teachers' education in computer ergonomics. Ergonomics, 50, 1657-1667.
Eggermont, S. and van den Bulck, J., 2006. Nodding off or switching off? The use of popular media as a sleep aid in secondary-school children. Journal of Paediatrics and Child Health, 42, 428-433.

Escobar-Chaves, S.L., et al., 2005. Impact of the media on adolescent sexual attitudes and behaviours. Pediatrics, 116, 303-326.

Faucett, J. and Rempel, D., 1994. VDT-related musculoskeletal symptoms: interactions between work posture and psychosocial work factors. American Journal of Industrial Medicine, 26, 597-912.

Foehr, U., 2006. Media multitasking among American youth: prevalence, predictors and pairings. Menlo Park, USA: Kaiser Family Foundation.

Funk, J.B., 2005. Video games. Adolescent Medicine Clinics, $16,395-411$.

Graves, L., et al., 2007. Comparison of energy expenditure in adolescents when playing new generation and sedentary computer games; Cross sectional study. British Medical Journal, 335, 1282-1284.

Green, C.S. and Bavelier, D., 2007. Action-video-game experience alters the spatial resolution of vision. Psychological Science, 18, 88-94.

Hakala, P.T., et al., 2006. Frequent computer-related activities increase the risk of neck-shoulder and low back pain in adolescents. European Journal of Public Health, $16,536-541$.

Hamilton, A.G., Jacobs, K., and Orsmond, G., 2005. The prevalence of computer-related musculoskeletal complaints in female college students. Work, 24, 387-394.

Harreby, M., et al., 1995. Are radiologic changes in the thoracic and lumbar spine of adolescents' risk factors for low back pain in adults? A 25-year prospective cohort study of 640 school children. Spine, 20, 2298-2302.

Harris, C. and Straker, L., 2000. Survey of physical ergonomics issues associated with school children's use of laptop computers. International Journal of Industrial Ergonomics, 26, 337-347.

Harris, C., et al., 2005. Musculoskeletal outcomes in children using Information Technology - the need for a specific etiological model. International Journal of Industrial Ergonomics, 35, 115-130.

Harrison, C., et al., 2002. ImpaCT2: The impact of information and communication technologies on pupil learning and attainment [online]. London: British Educational Communications and Technology Agency. Available from: http://partners.becta.org.uk/ index.php?section $=$ rh\&rid $=13606$ [Accessed 18 February 2008].

Hasselbring, T.S. and Williams Glaser, C.H., 2000. Use of computer technology to help students with special needs. The Future of Children, 10, 102-122.

Heft, T.M. and Swaminathan, S., 2002. The effects of school computers on the social behaviour of preschoolers. Journal of Research in Childhood Education, 16, $162-174$.

Ho, S. and Lee, T., 2001. Computer usage and its relationship with adolescent lifestyle in Hong Kong. Journal of Adolescent Health, 29, 258-266.

Hünting, W., Läubli, T., and Grandjean, E., 1981. Postural and visual loads at VDT workplaces I: Constrained postures. Ergonomics, 24, 917-931.

Jacobs, K. and Baker, N.A., 2002. The association between children's computer use and musculoskeletal discomfort. Work, 18, 221-226. 
Jacobs, K., Hudak, S., and McGiffert, J., 2003. Musculoskeletal complaints by middle school students with computer use [online]. Available from: www.iea.cc/ergonomics4children/pdfs/art0210.pdf [Accessed 20 February 2008].

Janssen, I., et al., 2005. Comparison of overweight and obesity prevalence in school-aged youth from 34 countries and their relationships with physical activity and dietary patterns. Obesity Reviews, 6, 123-132.

Kaiser Family Foundation, 2004. The role of media in childhood obesity. Menlo Park, USA: Kaiser Family Foundation.

Katz, J.M., et al., 2000. Prevalence of upper extremity musculoskeletal disorders in college students. American Journal of Medicine, 109, 586-588.

Kautiainen, S., et al., 2005. Use of information and communication technology and prevalence of overweight and obesity among adolescents. International Journal of Obesity, 29, 925-933.

Kent, N. and Facer, K., 2004. Different worlds? A comparison of young people's home and school ICT use. Journal of Computer Assisted Learning, 20, 440-455.

Kerawalla, L. and Crook, C., 2002. Children's computer use at home and school: Context and continuity. British Educational Research Journal, 28, 751-771.

Kerr, C.M. and Tappin, D.M., 2002. Do poor nutrition and display screens affect visual acuity in children? British Journal of Community Nursing, 7, 80-89.

Koivusilta, L.K., Lintonen, T.P., and Rimpelä, A.H., 2007. Orientations in adolescent use of information and communication technology: A digital divide by sociodemographic background, educational career and health. Scandinavian Journal of Public Health, 35, 95-103.

Laeser, K.L., Maxwell, L.E., and Hedge, A., 1998. The effect of computer workstation design on student posture. Journal of Research on Computing in Education, 31, 173-188.

Lajunen, H-R., et al., 2007. Are computer and cell phone use associated with body mass index and overweight? A population study among twin adolescents. BMC Public Health, 7, 24-31.

Lanningham-Foster, L., et al., 2006. Energy expenditure of sedentary screen time compared with active screen time for children. Pediatrics, 118, 1831-1835.

Lewis, D., 2003. Computers in patient education. Computers, Informatics, Nursing, 21, 88-96.

Koskelo, R., Vuorikari, K., and Hanninen, O., 2007. Sitting and standing postures are corrected by adjustable furniture with lowered muscle tension in high-school students. Ergonomics, 50, 1643-1656.

McColgan, M.D. and Giardino, A.P., 2005. Internet poses multiple risks to children and adolescents. Pediatric Annals, 34, 405-414.

Maddison, R., et al., 2007. Energy expended playing video console games: An opportunity to increase children's physical activity? Pediatric Exercise Science, 19, 1-24

Marcus, M., et al., 2002. A prospective study of computer users: II. Postural risk factors for musculoskeletal symptoms and disorders. American Journal of Industrial Medicine, 41, 236-249.

Marshall, S.J., et al., 2004. Relationships between media use, body fatness and physical activity in children and youth: a meta-analysis. International Journal of Obesity, 28, $1238-1246$.

Maslen, B. and Straker, L., 2009. A comparison of posture and muscle activity means and variation amongst young children, older children and young adults whilst working with computers. Work, 32, 311-320.
Menéndez, C.C., et al., 2007. A multi-method study evaluating computing-related risk factors among college students. Work, 28, 287-297.

Moseley, D., Mearns, N., and Tse, H., 2001. Using computers at home and in the primary school: Where is the value added? Educational and Child Psychology, 18, 31-46.

Motl, R.W., et al., 2006. Naturally occurring changes in time spent watching television are inversely related to frequency of physical activity during early adolescence. Journal of Adolescence, 29, 19-32.

Murphy, S., Buckle, P., and Stubbs, D., 2007. A crosssectional study of self-reported back and neck pain among English schoolchildren and associated physical and psychological risk factors. Applied Ergonomics, 38, 797-804.

Nalwa, K. and Anand, A.P., 2003. Internet addiction in students: A cause of concern. CyberPsychology and Behaviour, 6, 653-656.

Oates, S., Evans, G.W., and Hedge, A., 1998. An anthropometric and postural risk assessment of children's school computer work environments. Computers in the Schools, 14, 55-63.

Orleans, M. and Laney, M.C., 2000. Children's computer use in the home: Isolation or sociation? Social Science Computer Review, 18, 56-72.

Pollock, C. and Straker, L., 2008. Information and communication technology in schools. In: R. Lueder and V. Rice, eds. Child ergonomics. Boca Raton, FL: Taylor and Francis Group, 783-800.

Punamäki, R-L., et al., 2007. Use of information and communication technology (ICT) and perceived health in adolescence: The role of sleeping habits and waking-time tiredness. Journal of Adolescence, 30, 569-585.

Ramos, E.M.A., James, C.A., and Bear-Lehman, J., 2005. Children's computer usage: Are they at risk of developing repetitive strain injury? Work, 25, 143-154.

Reid, D.T., 2002. The use of virtual reality to improve upper-extremity efficiency skills in children with cerebral palsy: A pilot study. Technology and Disability, 14, 53-61.

Rideout, V.J., Vandewater, E.A., and Wartella, E.A., 2003. Zero to six: Electronic media in the lives of infants, toddlers and preschoolers. Menlo Park, USA: Kaiser Family Foundation.

Roberts, D.F., Foehr, U.G., and Rideout, V.J., 2005. Generation M: Media in the lives of 8-18 year-olds. Menlo Park, USA: Kaiser Family Foundation.

Roberts, D.F., et al., 1999. Kids and media@ the new millennium. Menlo Park, USA: Kaiser Family Foundation.

Robinson, T.N., 1999. Reducing children's television viewing to prevent obesity: A randomized controlled trial. Journal of the American Medical Association, 282, 15611567.

Rocheleau, B., 1995. Computer use by school age children: trends, patterns and predictors. Journal of Educational Computing Research, 12, 1-17.

Rosser, J.C., et al., 2007. The impact of video games on training surgeons in the 21st century. Archives of Surgery, 142, 181-186.

Scaife, M. and Bond, R., 1991. Developmental changes in children's use of computer input devices. Early Child Development and Care, 69, 19-38. 
Shields, M.K. and Behrman, R.E., 2000. Children and computer technology: Analysis and recommendations. The Future of Children, 10, 4-30.

Sillanpää, J., et al., 2003. Effect of work with visual display units on musculo-skeletal disorders in the office environment. Occupational Medicine, 53, 443-451.

Skotte, J.H., et al., 2007. Eye blink frequency during different computer tasks quantified by electrooculography. European Journal of Applied Physiology, 99, 113-119.

Sommerich, C.M., et al., 2007. A survey of high school students with ubiquitous access to tablet PCs. Ergonomics, 50, 706-727.

Sotoyama, M., et al., 2002. An ergonomic questionnaire survey on the use of computers in schools. Industrial Health, 40, 135-141.

Straker, L. and Abbott, R., 2007. Effect of screen based media on energy expenditure and heart rate in 9- to 12-year old children. Pediatric Exercise Science, 19, 459-471.

Straker, L.M. and Mathiassen, S.E., 2009. Increased physical loads in modern work - a necessity for better health and performance? Ergonomics, 52 (10), 1215-1225.

Straker, L. and Pollock, C., 2003. Delivering the power of computers to children, without harming their health (invited keynote address). In: CD ROM proceedings of 'Ergonomics in the Digital Age' the 15th triennial congress of the International Ergonomics Association, ISBN 8990838-10-X 98530, 24-29 August, Seoul, Korea.

Straker, L. and Pollock, C., 2005. Optimising the interaction of children with information and communication technologies. Ergonomics, 48, 506-521.

Straker, L., Pollock, C., and Burgess-Limerick, R., 2005. Towards evidence based guidelines for healthy \& wise use of computers by children. In: A. Thatcher, J. James, and A. Todd, eds. Proceedings of CybErg 2005: The fourth international cyberspace conference on ergonomics. Johannesburg: International Ergonomics Association.

Straker, L., Pollock, C., and Burgess-Limerick, R., 2006a. Excerpts from CybErg 2005 discussion on preliminary guidelines for wise use of computers by children. International Journal of Industrial Ergonomics, 36, 1089-1095.

Straker, L., Pollock, C., and Burgess-Limerick, R., 2006b. Towards evidence based guidelines for healthy \& wise use of computers by children. International Journal of Industrial Ergonomics, 36, 1045-1053.

Straker, L.M., et al., 2006c. The association between information and communication technology exposure and physical activity, musculoskeletal problems and socio-economic status in 5-year-olds. Child: Care, Health and Development, 32, 343-351.

Straker, L.M., et al., 2007. Computer use and habitual spinal posture in Australian adolescents. Public Health Reports, $122,634-643$.

Straker, L., et al., 2008a. Children's posture and muscle activity at different computer display heights and during paper information technology use. Human Factors, 50, 49-61.

Straker, L., et al., 2008b. A comparison of posture and muscle activity during tablet computer, desktop computer and paper use by young children. Ergonomics, 51, $540-555$.

Straker, L., et al., in press. The effect of forearm support on children's head, neck and upper limb posture and muscle activity during computer use. Journal of Electromyography and Kinesiology. DOI: 10.1016/j.jelekin.2008. 02.003 .
Straker, L., et al., 2009a. Children have less variable postures and muscle activities when using new electronic information technology compared with old paper based information technology. Journal of Electromyography and Kinesiology, 19, e132-e143.

Straker, L., et al., 2009b. Effect of visual display height on modelled upper and lower cervical gravitational moments, muscle capacity and relative strain. Ergonomics, 52 (2), 204-221.

Subrahmanyam, K., et al., 2000. The impact of home computer use on children's activities and development. The Future of Children, 10, 123-144.

Sveistrup, H., 2004. Motor rehabilitation using virtual reality. Journal of Neuroengineering and Rehabilitation, 1, $10-18$.

Szeto, G.P.Y., 2003. Potential health problems faced by an Asian youth population with increasing trends for computer use [online]. Available from: www.iea.cc/ ergonomics4children/sumtab.html [Accessed 2 April 2008].

Szeto, G.P.Y. and Sham, K.S.W., 2008. The effects of angled positions of computer display screen on muscle activities of the neck-shoulder stabilizers. International Journal of Industrial Ergonomics, 38, 9-17.

Tan, N.W., et al., 2000. Temporal variations in myopia progression in Singaporean children within an academic year. Optometry \& Vision Science, 77 (9), 465-472.

Turkle, S., 1995. Life on the screen: Identity in the age of the Internet. New York: Simon and Schuster.

US Department of Justice, 1997. Report on the availability of bomb-making information [online]. Available from: http:// www.cybercrime.gov/bombmakinginfo.html\#IB [Accessed 21 March 2008].

Vandewater, E.A., Shim, M., and Caplovitz, A.G., 2004. Linking obesity and activity level with children's television and video game use. Journal of Adolescence, 27, 71-85.

Villani, S., 2001. Impact of media on children and adolescents: A 10-year review of the research. Journal of the American Academy of Child and Adolescent Psychiatry, 40, 392-401.

Wake, M., Hesketh, K., and Waters, E., 2003. Television, computer use and body mass index in Australian primary school children. Journal of Paediatric Child Health, 39 , 130-134.

Wartella, E.A. and Jennings, N., 2000. Children and computers: New technology - old concerns. The Future of Children, 10, 31-43.

Wartella, E., O'Keefe, B., and Scantlin, R., 2000. Children and interactive media: A compendium of current research and directions for the future. USA: Markle Foundation.

Whitcomb, G.R., 1990. Computer games for the elderly. In: Proceedings of the conference on computers and the quality of life, 13-16 September 1990, Washington, USA. New York: ACM Press.

Williams, I.M., 2002. Students' musculoskeletal and visual concerns. In: The proceedings of the XVI annual international occupational ergonomics and safety conference, 9-12 June 1990, Toronto, Canada. Windsor, ON, Canada: International Society for Occupational Ergonomics and Safety.

Wolak, J., Mitchell, K., and Finkelhor, D., 2007. Unwanted and wanted exposure to online pornography in a national sample of youth internet users. Pediatrics, 119, $247-257$. 
Yan, Z. and Fischer, K.W., 2004. How children and adults learn to use computers: A developmental approach. New Directions for Child and Adolescent Development, 105, 41-61.

Yan, Z., et al., 2008. Computer Vision Syndrome: A widely spreading but largely unknown epidemic among computer users. Computers in Human Behaviour, 24, 2026-2042.
Yuji, H., 1996. Computer games and information processing skills. Perceptual and Motor Skills, 83, 643-647.

Zandvliet, D. and Straker, L., 2001. Physical and psychosocial aspects of the learning environment in information technology rich classrooms. Ergonomics, 44, 838-857. 